Document downloaded from:

http://hdl.handle.net/10251/50507

This paper must be cited as:

Jiménez Bello, MA.; Ballester, C.; Castel Sanchez, R.; Intrigliolo Molina, DS. (2011). Development and validation of an automatic thermal imaging process forassessing plant water status. Agricultural Water Management. (98):1497-1504. doi:10.1016/j.agwat.2011.05.002.



The final publication is available at

http://dx.doi.org/10.1016/j.agwat.2011.05.002

Copyright Elsevier Masson 


\section{Development and validation of an automatic thermal imaging process for assessing plant water status}

By: M.A. Jiménez-Bello ${ }^{1 *}$, C. Ballester ${ }^{1}$, J.R. Castel $^{1}$ and D.S. Intrigliolo ${ }^{1}$

1) Instituto Valenciano Investigaciones Agrarias (IVIA), Centro Desarrollo Agricultura Sostenible, P.O. Box 46113, Moncada, Valencia, Spain

* Author for correspondence, Tel. +34 96342400 Fax +34 963424001 e-mail address: mijibar@dihma.upv.es

Running title: Thermal imaging processing 


\section{ABSTRACT}

Leaf temperature is a physiological trait that can be used for monitoring plant water status. Nowadays, by means of thermography, canopy temperature can be remotely determined. In this sense, it is crucial to automatically process the images. In the present work, a methodology for the automatic analysis of frontal images taken on individual trees was developed. The procedure can be used when cameras take at the same time thermal and visible scenes, so it is not necessary to reference the images. In this way, during the processing in batch, no operator participated. The procedure was developed by means of a non supervised classification of the visible image from which the presence of sky and soil could be detected. In case of existence, a mask was performed for the extraction of intermediate pixels to calculate canopy temperature by means of the thermal image. At the same time, sunlit and shady leaves could be detected and isolated. Thus, the procedure allowed to separately determine canopy temperature either of the more exposed part of the canopy or of the shaded portion. The methodology developed was validated using images taken in several regulated deficit irrigation trials in Persimmon and two citrus cultivars (Clementina de Nules and Navel Lane-Late). Overall, results indicated that similar canopy temperatures were calculated either by means of the automatic process or the manual procedure. The procedure developed allows to drastically reduce the time needed for image analysis also considering that no operator participation was required. This tool will facilitate further investigations in course for assessing the feasibility of thermography for detecting plant water status in woody perennial crops with discontinuous canopies. Preliminary results reported indicate that the type of crop evaluated has an important influence in the results obtained from termographic imagery. Thus, in Persimmon trees there were good 
correlations between canopy temperature and plant water status while, in Clementina de Nules and Navel Lane-Late citrus cultivars canopy temperature differences among trees could not be related with tree-to-tree variation in plant water status.

\section{Keywords}

Image analysis, regulated deficit irrigation, thermography, water relations. 


\section{1- Introduction}

Efficient irrigation scheduling procedures require the analysis of plant water status. Leaf water potential measured with the pressure chamber, either at predawn or at midday, has long been used as a plant water stress indicator. More recently, the use of water potential of bag covered leaves, named stem water potential $\left(\Psi_{\mathrm{s}}\right)$ has been adopted because of its high sensitivity to water deprivation (McCutchan and Shackel, 1992) and its good prediction of the yield response to deficit irrigation (Naor, 2000). Particularly in fruit trees, $\Psi_{\mathrm{s}}$ has been used to modify the irrigation regime avoiding severe plant water stress situations (Lampinen et al. 2001). Midday stem water potential is then considered the reference measurement of plant water status but it is quite time and labor consuming what often limits its use. It is important then to look for alternatives to determine plant water status from techniques that could be potentially automated.

Transpiration is an endo-energetic thermodynamic process. When water is transpired by plants, the latent heat of evaporation is drawn from them, decreasing thereby their temperature. Plants under soil water limitations often respond decreasing stomatal conductance (gs), reducing hence transpiration. This implies that canopy temperature should raise in plants grown under soil water limitations. Therefore infrared sensing of the canopy temperature can be used to estimate gs and plant evapotranspiration (Jackson, 1982; Jones, 1999; Merlot et al., 2002; Jones et al., 2002).

Infrared thermography is a powerful tool to estimate crop temperatures. Images can be taken by thermographic cameras carried on airborne platforms (Berni et al., 2009) or by hand operated cameras where images are taken manually in the field assisted with auxiliary devices as tripods, platforms or cranes (Moller et al. 2007). Aerial images 
normally cover a large surface area according to the camera field of view and flight height. Afterwards images are radiometrically calibrated, georeferenced and atmospheric corrections applied. . Hand-operated cameras allow taking images of individual plants or even portions of them, achieving therefore higher spatial resolution. For instance, images can capture different tree parts (shady, sunlit or zenithal positions). Subsequently, images are processed, without the need of georeferentiation if crops are identified previously in the field and linked to their corresponding images.

In order to make this technique more useful for assessing crop water status, the automation of the images analysis is required. This is particularly important in the case of woody perennial crops that often have discontinuous canopies (i.e. ground cover is less than 100\%). In this case images can contain both canopy and soil portions that need to be separated. A few attempts to do this task have been described. For example, Leinonen and Jones (2004) used software of the remote sensing environment as ENVI (Research Systems Inc, Boulder, Colorado, USA) for the image analysis. The procedure consisted in taking an infrared image of the crop and another one in the red and infrared bands with a camera designed for that purpose. Images were overlapped by means of an orthorectification process, image pixels were classified and the vegetation identified by supervised classification techniques, and finally using the vegetation as a mask, the temperature was extracted from the thermal image. This procedure is relatively time consuming as it involves the participation of an operator in the orthorectification process and the selection of spectral signatures to feed the supervised classification. Subsequently, Cohen et al (2005) converted the thermal images to a grey scale. The images were exported with ThermaCamExplorer (FLIR Systems, Boston, USA) and were converted to 8 bits uncompressed TIFF format. Afterwards the spatial analysis 
was performed by means of the IMAGINE 8,7 software (Leica Inc, Wetzlar, Germany ). Finally the interest areas were manually selected and their temperatures calculated. More recently, Wang et al (2010) developed a methodology where firstly an infrared thermal image was overlaid with an optical image. With the aim of identifying vegetation, leaf color was assumed to follow a Gaussian distribution in HSV space (hue, saturation and value), where vegetation was identified by its mean and covariance. Then temperature statistics were calculated. In addition, the procedure developed by Wang et al. (2010) allowed to calculate dry and wet reference leaves in order to compute the crop water stress index (CWSI) as described by Jones et al (2002). In order to ensure that objects different from a leaf were not included in the temperature calculation routines a Gaussian mixture temperature distribution approach was used. However, the mean and covariance that characterize the spectral signature of vegetation can differ from one image to another due to several factors as vegetation type, sunlight intensity or the presence of shadows on the image. A methodology that will avoid the characterization of vegetation for each image analysis would be desirable to process in batch.

In this work, a routine has been developed where vegetation temperature is calculated with the help of a color image. The routine can be applied to any camera that takes a color and an infrared image at the same time in order to avoid any time consuming because no alignment procedures are required. Objects in the scene are classified into classes using an unsupervised classification method of the color image. Classes are identified by means of its vector in the red, green and blue model (RGB) and they are grouped according to their intensity. As a consequence, no operator participates in the analysis phase and images are processed in a sequential way. The methodology has been implemented using ArcGIS 9.x (ESRI, Redlands, USA) a commercial software and its 
developing platform named ArcObjects. Examples of the validation of this procedure are reported and results obtained in different irrigation trials are also presented and briefly discussed.

\section{Materials and methods}

\subsection{Experimental orchards}

The experiment was performed during 2009 in three commercial orchards of Persimmon (Diospyros kaki L.f.), Clementina de Nules (Citrus clementina, Hort ex Tan) and Navel Lane Late (Citrus sinensis (L) Osbeck), located in Manises, Liria and Chulilla (Valencia, Spain), respectively.

The Persimmon orchard was planted in 2001 with the cv 'Rojo Brillante' grafted on Diospyros lotus at 5.5 by $4 \mathrm{~m}$. During the experimental period trees had, on average, a shaded area of $39 \%$. The soil was sandy loam to sandy clay loam, calcareous; with an effective depth of $0.8 \mathrm{~m}$. Trees were drip-irrigated with two laterals per row and 8 emitters $(4 \mathrm{~L} / \mathrm{h})$ per tree. Two irrigation treatments were applied in this orchard: a) Control, irrigated at $100 \%$ of the estimated crop evapotranspiration (ETc) defined by Allen et al (1998); during the whole season with a total amount of water applied of 487 $\mathrm{mm}$, and b) RDI, irrigated at $50 \%$ of ETc from July (DOY 185) to August (DOY 230) with a total amount of water applied of $429 \mathrm{~mm}$. The statistical design was a complete randomised block with three replicate plots per treatment and 6-7 sampling trees per replicate. Other details about the orchard design and treatments lay out can be found in Badal et al. (2010). 
The orchards with Clementina de Nules (CN) and Navel Lane Late (NLL) were planted in 1999 and 2000, respectively, at 6 by $4 \mathrm{~m}$ and grafted on Carrizo citrange (Citrus sinensis, Osb. x Poncirus trifoliata, Raf.). At the beginning of the experiment, $\mathrm{CN}$ trees had an average shaded area of $37 \%$ and NLL trees of $32 \%$. Trees were drip irrigated with two laterals per row and 8 emitters $(4 \mathrm{~L} / \mathrm{h})$ per tree. The statistical design was a randomised complete block with four replicate plots per treatment. Each plot had three rows and perimeter trees were used as a guard, so 5-10 sampling trees per replicate plot were used in CN and NLL, respectively. Other orchard and experimental characteristics are described in more detail in Ballester et al (2008). The same irrigation treatments were applied in both orchards: a) Control, irrigated at 100\% of ETc during the whole season, b) RDI-1, irrigated at 50\% of ETc from July (DOY 209) to September (DOY 257) in CN and from July (DOY 201) to the end of September (DOY 271) in NLL, and

c) RDI-2, irrigated at $30-40 \%$ of ETc during the same periods as RDI- 1 . The seasonal amount of water applied averaged for the two orchards was $491 \mathrm{~mm}, 425 \mathrm{~mm}$ and 417 $\mathrm{mm}$ for the Control, RDI-1 and RDI-2 treatments, respectively.

\section{2. $\quad 2.2$ Tree water relations determinations}

Stem water potential $\left(\Psi_{\mathrm{s}}\right)$ was measured weekly at solar midday (12:00 h GMT) in all the orchards, using a pressure chamber (Model 600 Pressure Chamber Instrument, Albany, USA), following recommendations of Turner (1981). Two mature leaves of two trees per replicate plot, in the case of NLL and three trees per replicate plot, in the case of $\mathrm{CN}$ and Persimmon, were enclosed in plastic bags covered with silver foil at least two hours prior to the measurements. 
Stomatal conductance (gs) was measured with a leaf porometer (SC 1 Porometer, Decagon, WA, USA). In the case of Persimmon, measurements were taken in all the trees where $\Psi_{\mathrm{s}}$ was determined. In $\mathrm{CN}$ and NLL measurements were made only in Control trees and trees from the treatment with the more severe restrictions, RDI-2. Stomatal conductance of each tree was determined as the mean value of measurements taken in five different fully exposed leaves. Mean values of $\Psi_{\mathrm{s}}$ and of gs for each tree were compared with the thermal images taken simultaneously to the water status determinations.

\subsection{Acquisition of thermal images}

Thermal images were taken with an infrared thermal camera TH9100 WR (NEC San-ei Instruments, Tokyo, Japan) with a precision of $2{ }^{\circ} \mathrm{C}$ or $2 \%$ of reading. The camera had a visible of $752 \times 480$ pixels and a $320 \times 240$ pixel microbolometer sensor, sensitive in the spectral range of 8 and $14 \mu \mathrm{m}$ and a lens with an angular field of view of $42.0^{\circ} \times 32.1^{\circ}$. Emissivity used was 0.98 , a value characteristic of healthy vegetation (Monteith and Unsworth, 2008). Images were registered in a proprietary format denominated SIT where information is arranged in sections. Temperature is stored in a file of type "band sequential" (bsq) of 16 bits with temperature stored on 14 bits. Information referred to RGB format has a JPG format.

Thermal images were taken at solar noon in both, sunlight and shaded sides of all the trees where $\Psi_{\mathrm{s}}$ and gs were measured. In the case of Persimmon, images were taken in 8 different days (DOY 169, 204, 221, 225, 239, 246, 260 and 267) at a distance of 3 $\mathrm{m}$ from trees. A total of 344 images were taken. In citrus, images were taken at 1-2 $\mathrm{m}$ of 
distance from trees. In the $\mathrm{CN}$ experiment images were taken in 5 different days (DOY 215, 229, 236, 260 and 267) making a total of 448 images taken. In the NLL experiment, images were taken in 7 different days (DOY 203, 217, 224, 231, 238, 245 and 252) with a total of 384 images. However, for the purpose of the present experiment only part of all the images taken on each crop were analysed..

\subsection{Methodology developed}

For the image analysis the ArcGIS 9.3 software (ESRI, Redlands, USA) was used. This software has an application called "Geoprocessing" which is a set of windows and dialog boxes used to manage and build models that execute a sequence of tools. These models can be customized and run by means of programming languages like Microsoft Visual Basic. In addition, it is possible to connect with a database (DB) to feed the processes developed in the ArcGIS environment and to store the results on the DB. The analysis process included the following steps (see algorithm in Fig. 1):

Images were catalogued and stored in the DB. Each image was clearly identified with the date and hour, treatment, replicate, tree and position (sunlit or shadow).

Images were selected by means of a query to the DB. This allows to analyse all the images captured in a day or for a selected irrigation treatment.

The SIT image format was exported to a standard format compatible with the software used. For that purpose, pixels with thermal information image were exported to the bsq format (ESRI, 2007) and pixels with RGB information were exported to JPG format. 
Thermal images were reclassified assigning to each pixel the corresponding temperature, in a binary code, according to the scale used by the camera. In this case, temperature range was $-50^{\circ} \mathrm{C}$ to $130^{\circ} \mathrm{C}$ and pixel temperature was calculated by the equation: $\mathrm{T}\left({ }^{\circ} \mathrm{C}\right)=40+\mathrm{DN} * 180 / 16384$, where $\mathrm{DN}$ is the 14 bits value, 40 is the temperature value for $\mathrm{DN}=0,180$ is the temperature range and 16384 the possible values of a 14 bits pixel.

Non supervised pixel classification of the RGB image was performed (Lillesand et al 2004). The reason was to avoid the presence of an operator in the spectral signatures selection phase. Normally, up to six classes appeared in a scene: clear sky, clouds, shadows, soil, shady vegetation and sunlit vegetation. In a supervised process, the operator has to assign a representative area to the classes presented in the image. Successively, the operator should calculate, for each selected class, a spectral signature in RGB. This consists of a vector of three dimensions where each component represents the red, blue and green bands (Fig. 2). This process has to be repeated for each single image analysis considering that scene features might differ among days and even among scenes taken in a same day. The possible number of different classes in a scene was tested concluding that, for more than 7 classes, the algorithm did not find enough pixels to identify a new class. The above mentioned six classes were identified, assigning the extra class to pixels of vegetation. In the absence of clouds and when the sky had different levels of intensity, the extra class was assigned to sky. An example of this classification, is shown in Fig. 3 where a photograph taken in the Persimmon orchard has been included.

Once the classes where set up, image was classified using a Maximum Likelihood Classification algorithm based on the Bayes theorem considering that each class is 
normally distributed in a multidimensional space (Lillesand et al 2004). The tool implemented in ArcGIS offered us the possibility of produce a raster file with 14 levels showing the interval of confidence of the pixel classification. For the images where neither sky nor soil were captured, classes were assigned within the shady and sunlit vegetation, representing the intermediate classes vegetation with different illumination intensities.

For each class, the RGB vector module was calculated. Each coordinate vector was defined by the pixel value in the RGB bands as shown in Fig. 2. These classes are ordered according to their intensity. The darkest classes, usually represent shadows, have a lower value.

Due to the low sky emissivity in clear days (Wunderlich 1972), pixels composing the sky classes show a lower average temperature and higher standard deviation than the other classes. In the case that sky would had been photographed, gravity centers of the darkest class and sky can be calculated and a polygonal can be created to overlap the intermediate pixels existing between both classes. The rest of pixels can then be excluded from the analysis to avoid possible errors in pixel classification (e.g. a sunlit soil zone could be misclassified as vegetation). The width of the mask was set taking into account the average distance from the camera to the tree and the camera field of view which determined the scale and the size of the photographed scene. This area must be lower than the canopy diameter, thus the target tree can be properly analysed (Fig. 4).

When sky was not detected in the scene, masking was not applied, nevertheless, a mask can be forced to include only an image zone. In the case that the mask was applied, the shadiest class gravity center was calculated. The image orientation (vertical 
or horizontal) was determined and the midpoint of the opposite edge was chosen as reference to build the polygon mask.

When sunlit leaves were chosen for temperature calculation, pixels with highest RGB module were selected. In case all pixels need to be included the whole selectable classes can be easily taken into account.

The minimum $\left(\mathrm{T}_{\min },{ }^{\circ} \mathrm{C}\right)$, maximum $\left(\mathrm{T}_{\max },{ }^{\circ} \mathrm{C}\right)$, average $\left(\mathrm{T}_{\mathrm{c}}{ }^{\circ} \mathrm{C}\right)$ and standard deviation $\left(\mathrm{T}_{\text {std }}{ }^{\circ} \mathrm{C}\right)$ of selected pixels were calculated. It is possible to exclude from the calculation those pixels not to be classified, for example those below a certain degree of confidence, making a mask with the confidence raster produced during the classification process. Output results were stored in the database together with $\Psi_{\mathrm{s}}$ and gs determined for each crop and date.

\subsection{Data analysis}

A comparison between canopy temperature calculated either manually or with the automatic procedure was performed in 44 images taken in different days and treatments in the Persimmon and $\mathrm{CN}$ trees. Linear regressions between pair of temperature calculation procedures were performed using the regression models "REG" procedure of the SAS statistical package (version 9.0; SAS Institute, Cary, NC). In addition differences between manual and automatic canopy temperature determinations were assessed by one-way ANOVA.

Tree-to-tree variations in midday stem water potentials were linearly related with the respective values of canopy temperature either manually or automatically computed. Finally, for each crop type and on a selected day of measurements, the effects of the 
irrigation regime on canopy temperature, $\Psi_{\mathrm{s}}$ and gs was evaluated by analysis of variance using the general linear models "GLM" procedure of the SAS software.

\section{3- Results and discussion}

\subsection{Automatic versus manual image processing}

In both Persimmon and Clementina de Nules citrus trees, the ANOVA results indicated that there were no statistically significant differences between canopy temperatures obtained either via automatic or manual procedures $(P$ values of 0.427 and 0.627 for Persimmon and CN trees, respectively).

The slopes of the linear regressions between pairs of $T_{c}$ computed either manually or automatically were not different from 1 (Fig. 5A Persimmon, Fig 5B CN) However, the intercepts ("a") were in both cases significantly different from zero. In Persimmon, "a" was -1.46 indicating a general underestimation of the $T_{c}$ when automatically calculated. This underestimation occurred in 36 images out of 44 that were taken to deliberately capture the whole tree. The reason for this underestimation is due to the fact that when the mask is created, some leaf pixels close to sky, together with some sky pixels misclassified as leaves, are included in the average $T_{c}$ computation. Since the sky has a lower emissivity than the leaves, this lead to an underestimation of temperature calculated automatically. This fact can be seen in Figure 6 where the T raster computed by means of a mask manually performed by an operator (Fig. 6A) and the $\mathrm{T}$ raster computed with a mask automatically created detecting the shadow and the sky (Fig 6B) are shown. The darkest pixels represent the lower temperatures. They are located on the 
canopy outline with the sky as background. This issue could be overcome taking photographs with higher resolution, where sky and leaves could be more clearly separated.

In contrast, in $\mathrm{CN}$ the intercept " $\mathrm{a}$ " was $=+1.40$, indicating overestimation of the temperature in the low range $\left(\mathrm{T}_{\mathrm{c}}<28^{\circ} \mathrm{C}\right)$ compared with those calculated manually. In this case images were taken at a closer distance from the tree. This fact involves the absence of sky in most of the scenes. An example of a $\mathrm{CN}$ image processed with a mask generated either, manually (Fig. 7 A) or automatically (Fig. 7 B) shows that mostly canopy leaves were taken in the $\mathrm{CN}$ photographs. For this reason, in $\mathrm{CN} \mathrm{T}_{\mathrm{c}}$ is distributed on both sides of the straight (1:1) line. In this case 30 images out of 44 automatically analysed slightly overestimated the temperature compared with those calculated manually by an average of $-0.31^{\circ} \mathrm{C}$.

Another validation of the procedure developed for automatically extracting $\mathrm{T}_{\mathrm{c}}$ from photographs was carried out comparing the relationships between $\Psi_{\mathrm{s}}$ and $\mathrm{T}_{\mathrm{c}}$ either manually or automatically determined (Fig. 8 and 9). In Persimmon, for the two days (Fig 8 A DOY 169, Fig 8 B DOY 204) when this analysis was performed, there were statistically significant relationships between $\Psi_{\mathrm{s}}$ and $\mathrm{T}_{\mathrm{c}}$. Despite the degree of correlation between the plant water status indicators varied among days, similar values of the coefficient of determination $\left(r^{2}\right)$ of the $T_{c}-\Psi_{s}$ were obtained for $T_{c}$ either manually or automatically calculated. In addition, it should be remarked that differences in both slopes and intercepts of the regression lines obtained from $\mathrm{T}_{\mathrm{c}}$ either manually or automatically calculated were not statistically significant (at $\mathrm{P}<0.05$ or higher) on any day and crop. 
The time saving obtained by the automatic procedure is important considering that the manual analysis of a image takes an average of 17 minutes, whereas in the automatic way each image took about 1,1 minute to be processed (Intel Core 2 Duo, p8400 2.26 Ghz Memory Ram 4.00 GB) and operators do not have to participate during the analysis. The time for cataloguing and storing images in the database is the same for both methodologies. In addition, the automatisation makes possible to repeat the analysis as many times as required modifying the input parameters or changing the analysis conditions, without having to repeat the manual tasks every time these are modified.

\subsection{Physiological results}

Since the image analysis procedure here developed was succesfully validated, the whole set of 1176 images have been processed. This data set (results not shown) will be used to determine in further communications the feasibility of using $T_{c}$ obtained with a thermographic camera as a water stress indicator in both Persimmon and citrus trees.

In any case, an example of the type of results obtained by means of the automatic thermographic analysis is shown in Table 1. During the selected days, for similar water restrictions levels in the deficit irrigated treatments, Persimmon trees reached higher $T_{c}$ than citrus trees in response to water stress. This behaviour could be observed for both sunny and shaded leaves. In addition, the best relationships among $T_{c}$ versus $\Psi_{s}$ and gs were also observed in Persimmon (data not shown). The fact that in Persimmon $T_{c}$ was able to better detect differences in plant water status might be due to: i) different stomatal regulation in response to irrigation restrictions and ii) differences in leaf 
characteristics among crops, like leaf size and stomatal density, which affect the aerodynamic and indirectly stomatal conductances. In citrus trees, there were not differences in stomatal conductance between irrigation treatments, while in Persimmon gs was about half in the RDI trees than in the control, well-watered ones (Table 1). In addition, Persimmon trees have larger leaves than citrus what reduces the sensible heat exchange between the leaf and the environment. It seems then that the type of crop evaluated with thermal imagery has an important influence in the results obtained. In citrus trees, with smaller leaves and lower values of stomatal conductance, assessing crop water stress by canopy temperature is more complicated and less precise than in Persimmon trees. In previous experiments carried out in Vitis vinifera, a species with large leaves and generally high degree of stomatal regulation in response to soil drying, Jones et al. (2002) and Möller et al. (2007) showed that canopy temperature allowed to precisely estimate either gs or stem water potential.

\section{4- Conclusions}

A routine for automatic canopy temperature extraction based on an unsupervised classification method of the color image has been developed and validated. This automatic process allows obtaining quickly canopy temperature data from experiments or commercial situations, drastically reducing the time consumed for images analysis eliminating in addition any subjectivity due to the operator analysis. Indeed, the procedure here developed might facilitate the adoption of the thermography for crop water stress detection and irrigation scheduling. At a commercial scale it is important to automate the information extraction process in order to be able to actuate on irrigation 
controllers. The routine proposed might serve as a first step in order to finally incorporate canopy temperature determinations by thermography in the irrigation scheduling automation.

\section{Acknowledgements}

This research was supported by funds from the Instituto Valenciano de Investigaciones Agrarias and the "Denominación de origen Caqui Ribera del Xúquer" via "Proyecto Integral Caqui”, from projects Rideco-Consolider CSD2006-0067 and Interreg IV Sudoe Telerieg. Thanks are also due to J. Castel, E. Badal, I. Buesa and D. Guerra for assistance with field work and to the Servicio de Tecnología del Riego for providing the meteorological data 


\section{References}

Allen, R.G., Pereira, L.S., Raes, D., Smith, M., 1998. Crop evapotranspiration: Guidelines for computing crop requirements. Irrigation and Drainage Paper No. 56, FAO, Rome, Italy.

Badal, E., Buesa, I., Guerra, D., Bonet, L., Ferrer, P. Intrigliolo, D.S. 2010. Maximum diurnal trunk shrinkage is a sensitive indicator of plant water, stress in Diospyros kaki (Persimmon) trees. Agric. Water Manage. 98, 143-147.

Ballester, C., Castel, J., Castel, J.R., 2008. Effects of Regulated Deficit Irrigation on 'Clementina de Nules' and 'Navel Lane Late' Citrus Trees: Growth, Yield and Fruit Quality. Proceedings of the International Society of Citriculture 1, 749-753.

Berni, J.A., Zarco-Tejada, P., Suárez L., Fereres, E.. 2009 Thermal and Narrowband Multispectral Remote Sensing for Vegetation Monitoring From an Unmanned Aerial Vehicle. Ieee Transactions on Geoscience and Remote Sensing 47 (3),722-738

Cohen Y., Alchanatis V., Meron M., Saranga Y., Tsipris J. 2005. Estimation of leaf water potential by thermal imagery and spatial analysis. Journal of Experimental Botany 56, 1843-1852.

ESRI 2007. ArcGIS 9.2 Desktop Help.URL://webhelp.esri.com/arcgisdesktop/9.2/

Idso, S.B., Jackson, R.D., Pinter, P.J., Reginato, R.J., Hatfield, J.L. (1981) Normalizing the stress-degree-day parameter for environmental variability. Agricultural Meteorology 24:45-55

Jones, H.G.. 1999. Use of infrared thermometry for estimation of stomatal conductance as a possible aid to irrigation scheduling. Agricultural and Forest Meteorology 95, 139-149 
Jones, H.G., Stoll, M., Santos, T., de Sousa, C., Chaves, M.M., Grant, O.M. 2002. Use of infrared thermography for monitoring stomatal closure in the field: application to grapevine. Journal of Experimental Botany 53, 2249-2260.

Lampinen, B.D., Shackel, K.A,. Southwick, S.M.,Olson, B. 2001 Deficit irrigation strategies using midday stem water potential in prune. Irrigation Science 20, 47-54.

Leinonen, I., Jones, H.G. 2004. Combining thermal and visible imagery for estimating canopy temperature and identifying plant stress. Journal of Experimental Botany, Vol. 55,. 1423-1431

Lillesand, T.S., Kiefer, R.W., Chipman, J.W. 2004. Remote Sensing and image interpretation, 5th edn. New York: John Wiley and Sons Inc.

McCutchan, H., Shackel, K.A. 1992 Stem water potential as a sensitive indicator of water stress in prune trees (Prunus domestica L. cv. French). Journal of the American Society of Horticultural Science 117, 607-611.

Merlot, S., Mustilli, A.C., Genty, B., North, H., Lefebvre, V., Sotta, B., Vavasseur, A., Giraudat, J. 2002. Use of infrared thermal imaging to isolate Arabidopsis mutants defective in stomatal regulation. The Plant Journal 30, 601-609.

Möller, M., Alchanatis, V., Cohen, Y., Meron, M., Tsipris, J., Ostrovsky, V. 2007. Use of thermal and visible imagery for estimating crop water status of irrigated grapevine. Journal of Experimental Botany, 58, 827-838

Monteith, J.L., Unsworth, M.H. 2008. Principles of environmental physics.: Elsevier/ Academic Press 440 pp.

Naor, A. 2000 Midday stem water potential as a plant water stress indicator for irrigation scheduling in fruit trees. Acta Horticulturae 537, 447-454. 
Turner, N. 1981. Techniques and experimental approaches for the measurement of plant water status. Plant and Soil, 58, 339-366

Wang, X., Yang, W., Wheaton, A., Cooley, N., Moran, B. 2010. Automated canopy temperature estimation via infrared thermography: A first step towards automated plant water stress monitoring Computers and Electronics in Agriculture 73, 74-83

Wunderlich, WO. 1972. Heat and mass transfer between a water surface and the atmosphere. Lab. Report No. 14, Tennessee Valley Authority Engineering Laboratories, Norris, TN. 


\section{Legend for figures}

Fig. 1 Flux diagram of the whole automatic thermal image processing algorithm.

Fig. 2 The additive color model Red, Green and Blue (RGB) in which red, green, and blue light are added together to reproduce a broad array of colors.

Fig. 3 Classification non supervised in seven classes of a RGB image of a Persimmon tree.

Fig. 4 Polygonal mask applied to a scene with sky and shadows.

Fig. 1 Comparison of manual and automatic calculation procedures of average canopy temperatures $\left(\mathrm{T}_{\mathrm{c}}\right)$ for a representative day where the coefficient of determination $\left(\mathrm{r}^{2}\right)$ and the linear regression equations are shown. A) Persimmon (DOY 204). B) CN (DOY 215). The solid lines in each figure represent the 1:1 relationship.

Fig. $2 \mathrm{~T}_{\mathrm{c}}$ calculated by different types of masks in a Persimmon tree. A) The mask is manually created by an operator. The operator draws the mask following the tree outline avoiding sky pixels selection. B) The mask is created automatically after sky and shadow detection. Pixels close to the tree outline are also selected.

Fig. $3 \mathrm{~T}_{\mathrm{c}}$ calculated by different types of masks in a $\mathrm{CN}$ tree. A) The mask is manually created by an operator to select vegetation. B) The mask is created automatically in a scene where sky is absent.

Fig 8 Linear equation and coefficient of determination $\left(\mathrm{r}^{2}\right)$ between temperature canopy $\left(\mathrm{T}_{\mathrm{c}},{ }^{\circ} \mathrm{C}\right)$ and stem water potential $\left(\Psi_{\mathrm{s}}, \mathrm{MPa}\right)$ for two days in the Persimmon experiment 
calculated by both automatic and manual method. Twelve trees were sampled by thermal imagery and $\Psi_{\mathrm{s}}$ determinations. A) DOY 169. B) DOY 204.

Fig 9 Linear equation and coefficient of determination $\left(\mathrm{r}^{2}\right)$ between temperature canopy $\left(\mathrm{T}_{\mathrm{c}},{ }^{\circ} \mathrm{C}\right)$ and stem water potential $\left(\Psi_{\mathrm{s}}, \mathrm{MPa}\right)$ for two days in the $\mathrm{CN}$ experiment calculated by both automatic and manual method. 36 trees were sampled by thermal imagery and $\Psi_{\mathrm{s}}$ measures. A) DOY 215. B) DOY 236. 
Table 1. Values of midday stem water potential $\left(\Psi_{\mathrm{s}}\right)$, stomatal conductance $(\mathrm{gs})$, canopy temperature $\left(T_{c}\right)$, temperature extracted from the sunlit leaves $\left(T_{c S u n}\right)$ and temperature extracted from the shady leaves $\left(\mathrm{T}_{\text {cShady }}\right)$ for each treatment in a representative day of the experiment in Clementina de Nules (DOY 237), Navel Lane Late (DOY 239) and Persimmon (DOY 226). Temperature measurement values of each treatment are average of 27 trees in Persimmon, 36 trees in Clementina de Nules and 24 trees in Navel Lane Late.

\begin{tabular}{|c|c|c|c|c|c|}
\hline Irrigation & & gs & & & \\
\hline treatment & $\Psi_{\mathrm{s}}(\mathrm{MPa})$ & $\left(\mathrm{mmol} \mathrm{m} \mathrm{s}^{-2} \mathrm{~s}^{-1}\right)$ & $\mathrm{T}_{\mathrm{c}}\left({ }^{\circ} \mathrm{C}\right)$ & $\mathrm{T}_{\mathrm{cSun}}\left({ }^{\circ} \mathrm{C}\right)$ & $\mathrm{T}_{\text {cShady }}\left({ }^{\circ} \mathrm{C}\right)$ \\
\hline \multicolumn{6}{|c|}{ Clementina de Nules } \\
\hline Control & $-1.14 c$ & 40.5 & $30.0 \mathrm{~b}$ & $30.2 b$ & $29.9 b$ \\
\hline RDI-1 & $-1.42 b$ & - & $30.4 \mathrm{ab}$ & $30.7 \mathrm{ab}$ & $30.5 \mathrm{ab}$ \\
\hline RDI-2 & $-1.61 \mathrm{a}$ & 38.1 & $30.9 \mathrm{a}$ & $31.1 \mathrm{a}$ & $30.9 a$ \\
\hline \multicolumn{6}{|c|}{ Navel Lane Late } \\
\hline Control & $-0.94 c$ & 48.9 & 31.9 & 32.8 & 31.8 \\
\hline RDI-1 & $-1.30 b$ & - & 32.0 & 32.8 & 31.9 \\
\hline RDI-2 & $-1.65 a$ & 46.2 & 32.1 & 33.0 & 32.1 \\
\hline \multicolumn{6}{|c|}{ Persimmon } \\
\hline Control & $-0.87 b$ & $174.2 \mathrm{a}$ & $32.0 \mathrm{~b}$ & $32.4 b$ & $30.7 b$ \\
\hline RDI & $-1.99 a$ & $94.3 b$ & $35.7 \mathrm{a}$ & $36.2 \mathrm{a}$ & $34.5 \mathrm{a}$ \\
\hline
\end{tabular}






Fig. 1 Flux diagram of the whole automatic thermal image processing algorithm. 


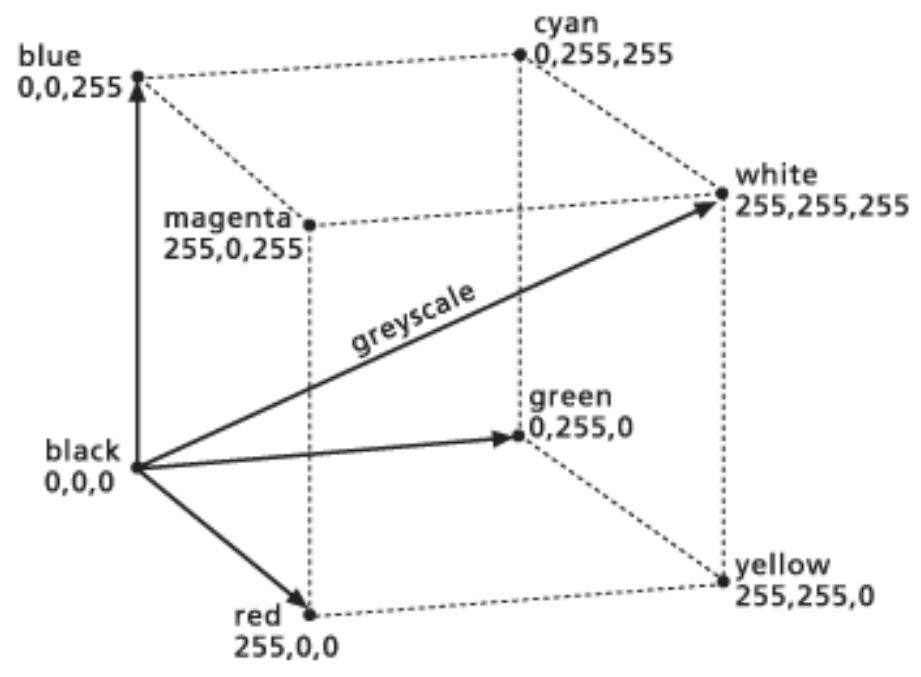

Fig. 2 The additive color model Red, Green and Blue (RGB) in which red, green, and blue light are added together to reproduce a broad array of colors 

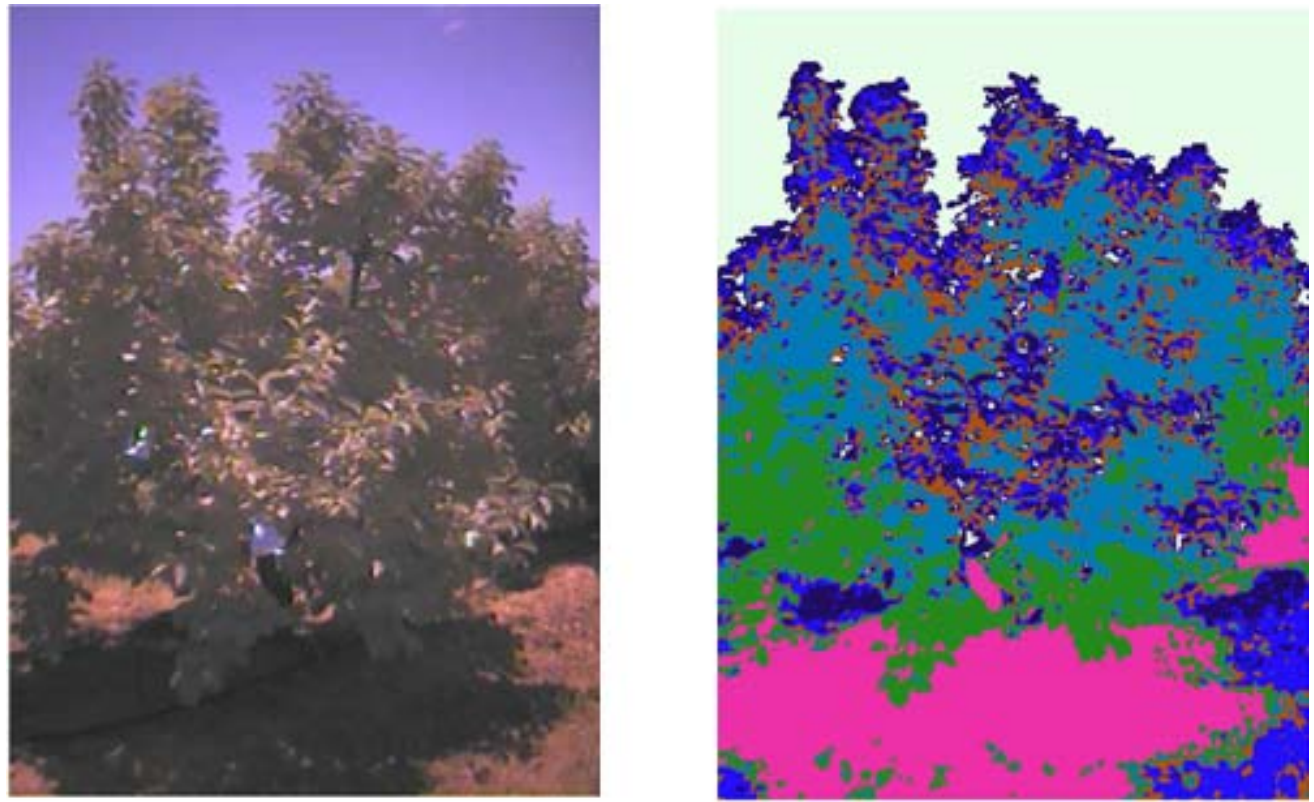

Fig. 3 Classification non supervised in seven classes of a RGB image of a Persimmon tree. 


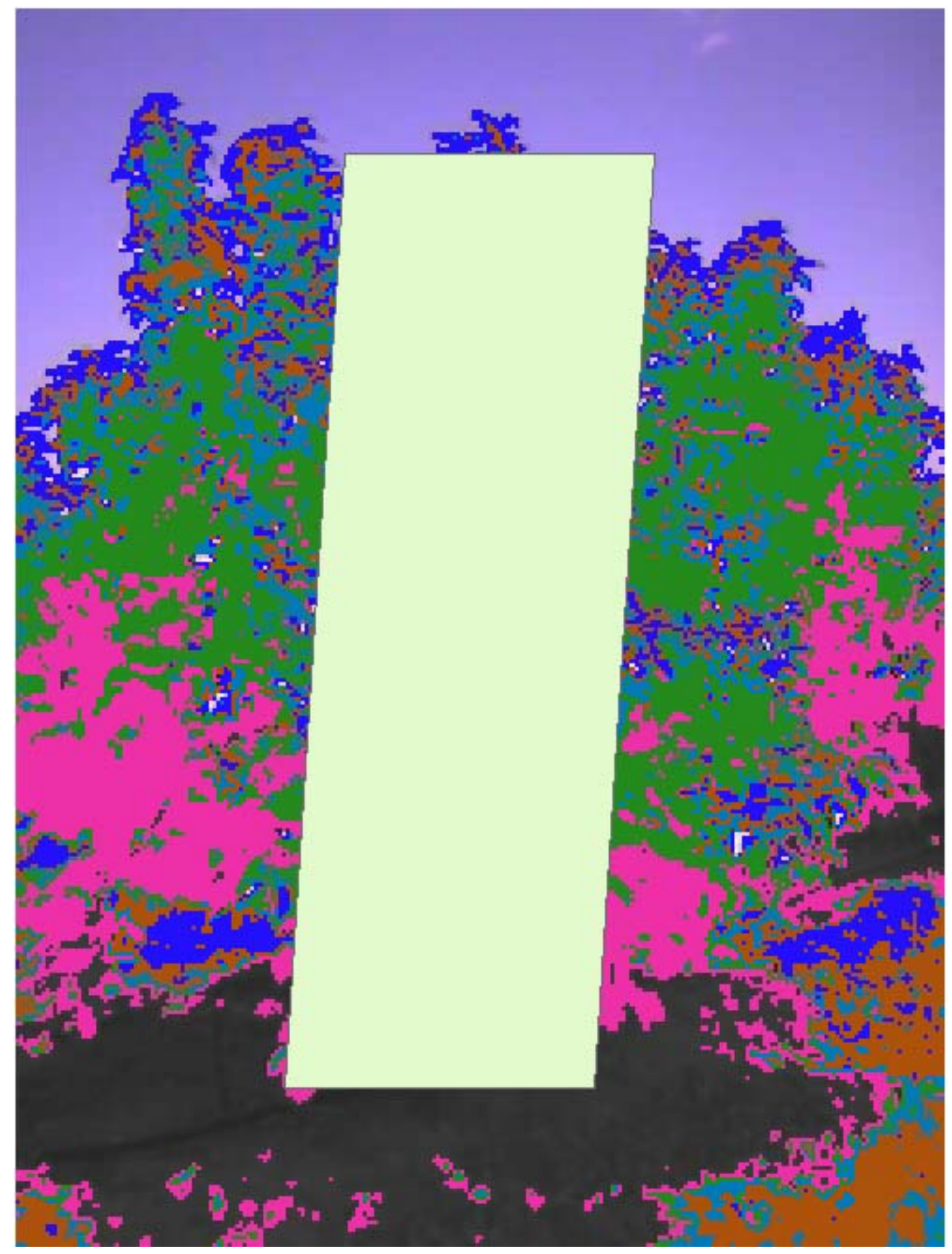

Fig. 4 Polygonal mask applied to a scene with sky and shadows. 

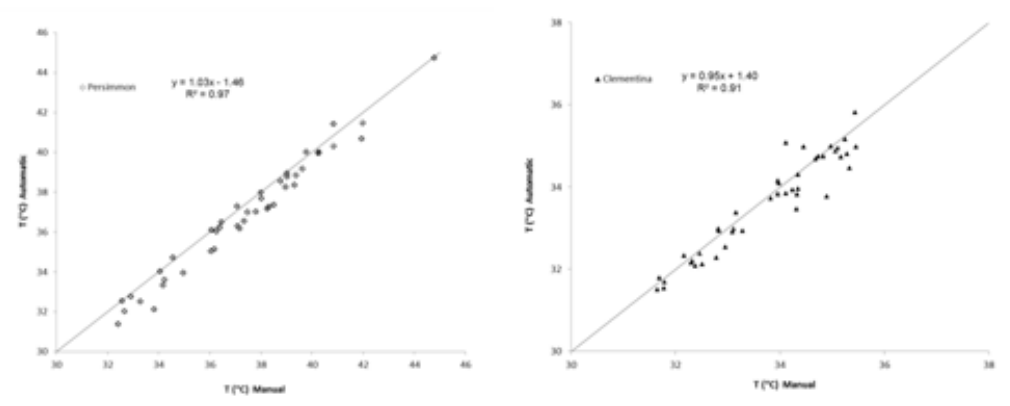

Fig. 4 Comparison of manual and automatic calculation procedures of average canopy temperatures $\left(\mathrm{T}_{\mathrm{c}}\right)$ for a representative day where the coefficient of determination $\left(\mathrm{r}^{2}\right)$ and the linear regression equations are shown. A) Persimmon (DOY 204). B) CN (DOY 215). The solid lines in each figure represent the 1:1 relationship. 

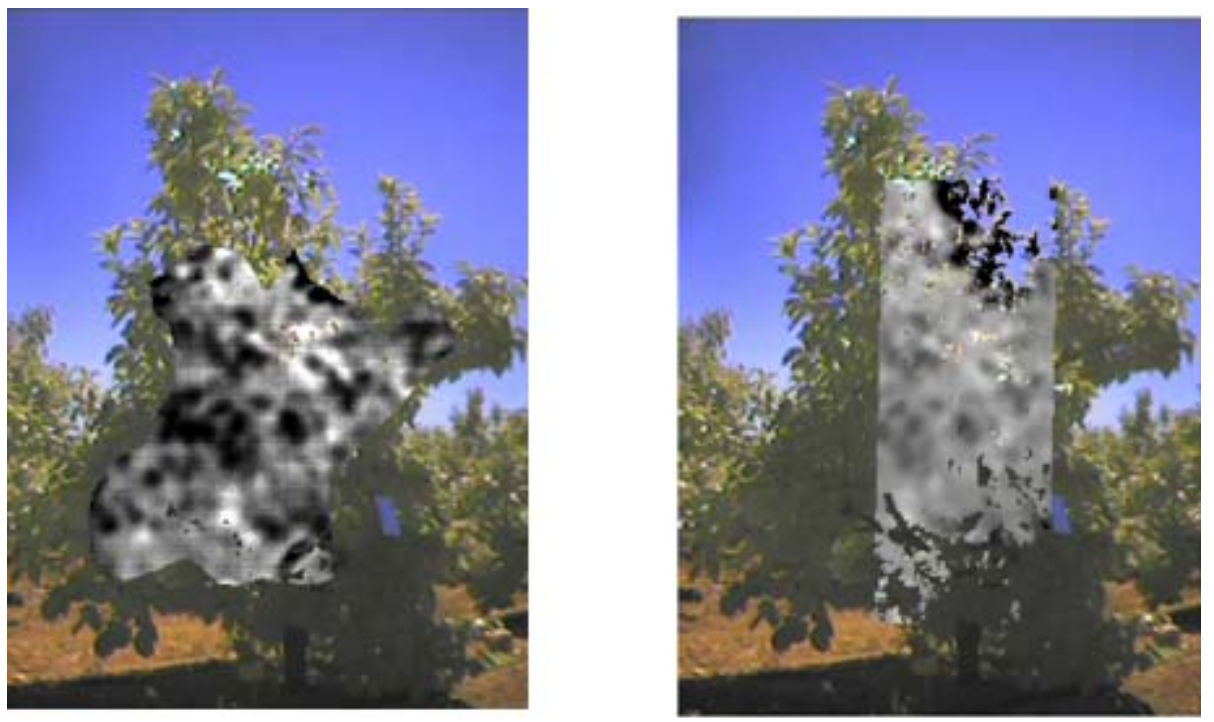

Fig. $5 \mathrm{~T}_{\mathrm{c}}$ calculated by different types of masks in a Persimmon tree. A) The mask is manually created by an operator. The operator draws the mask following the tree outline avoiding sky pixels selection. B) The mask is created automatically after sky and shadow detection. Pixels close to the tree outline are also selected. 

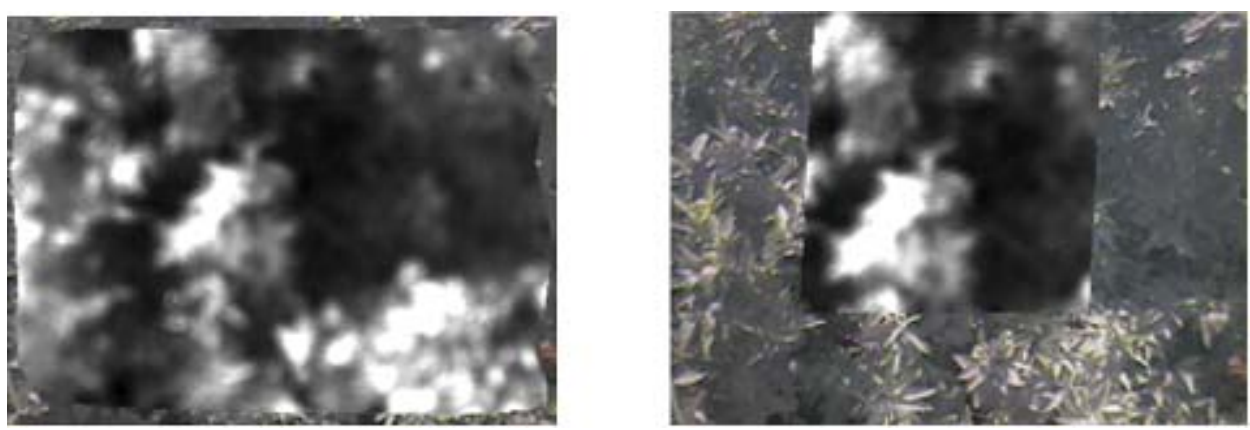

Fig. $6 \mathrm{~T}_{\mathrm{c}}$ calculated by different types of masks in a $\mathrm{CN}$ tree. A) The mask is manually created by an operator to select vegetation. B) The mask is created automatically in a scene where sky is absent. 

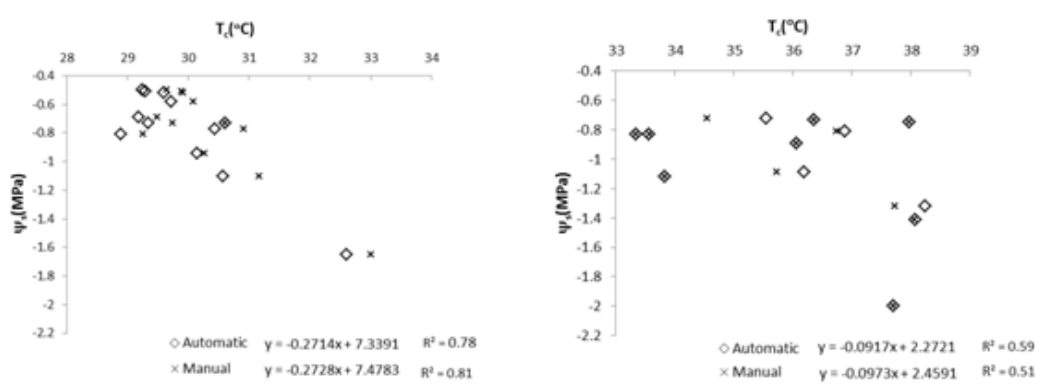

Fig 8 Linear equation and coefficient of determination $\left(\mathrm{r}^{2}\right)$ between temperature canopy $\left(\mathrm{T}_{\mathrm{c}},{ }^{\circ} \mathrm{C}\right)$ and stem water potential $\left(\Psi_{\mathrm{s}}, \mathrm{MPa}\right)$ for two days in the Persimmon experiment calculated by both automatic and manual method. Twelve trees were sampled by thermal imagery and $\Psi_{\mathrm{s}}$ determinations. A) DOY 169. B) DOY 204. 



Fig 9 Linear equation and coefficient of determination $\left(\mathrm{r}^{2}\right)$ between temperature canopy $\left(\mathrm{T}_{\mathrm{c}},{ }^{\circ} \mathrm{C}\right)$ and stem water potential $\left(\Psi_{\mathrm{s}}, \mathrm{MPa}\right)$ for two days in the $\mathrm{CN}$ experiment calculated by both automatic and manual method. 36 trees were sampled by thermal imagery and $\Psi_{\mathrm{s}}$ measures. A) DOY 215. B) DOY 236. 